\title{
Coastal Scenic Evaluation At Santa Catarina (Brazil): Implications For Coastal Management
}

Da Costa Cristiano, Samanta; Portz, Luana Carla;Anfuso, Giorgio; Rockett, Gabriela Camboim; Barboza Guimarães, Eduardo.

\begin{abstract}
Continuous and increasing human coastal occupations and developments, often linked to the lack of adequate management plans, seriously threat coastal and marine environments. The knowledge of natural aspects of coastal environments and human occupation characteristics is essential for adequate and sound coastal planning. The present research characterized 80 coastal sites scenic value along the South and Center-South coast of Santa Catarina (Brazil), which receive huge tourist arrivals during the summer season, i.e. from December to March. Coastal evaluation was carried out by means of the Scenery Evaluation System and information on conservation status, beach awards and human occupation level was also gathered. Sites located on the Central-South coast have higher D values due to their relevant physical characteristics, such as the presence of bays, cliffs, mountainous landscape, etc. being very different from those in the South, where the coast is low, rectilinear and unattractive. Class I represents c. $10 \%$ of the Center-South coast and class V c. 8\%. In the South, the situation is different and none of the sectors was assessed as class I or III, only one sector belongs to class II, and the rest are classified as class IV and V. Obtained information opens new viewpoints to local coastal managers for analysis of the potential for national and international coastal tourism development in: i) natural areas, taking into account that a growing category of beach goers prefer isolated sites of great scenic beauty, and ii) for scenic quality improvement of current tourist developed areas.
\end{abstract}

\section{Keywords}

Beaches; Coastal Engineering; Conservation; Employment. 